\title{
Impact of reinforcement on the load-settlement behavior of a strip footing adjacent to granular soil excavation
}

Hussein Ahmad ( $\nabla$ houssein.ah@gmail.com )

Tishreen University https://orcid.org/0000-0001-5115-4200

\section{Research Article}

Keywords: Load-bearing capacity, sheet pile, reinforced granular soils, strip footing, excavation

Posted Date: January 24th, 2022

DOI: https://doi.org/10.21203/rs.3.rs-1180557/v1

License: (c) (i) This work is licensed under a Creative Commons Attribution 4.0 International License.

Read Full License 


\section{Abstract}

By adding a geogrid, the granular soils are improved as far as their load-settlement behavior is concerned. It is often necessary to build new buildings adjacent to existing buildings because of a shortage of urban land. It is necessary, therefore, to excavate. An excavation's surface foundations have less information on their behavior. Two types of granular soil were employed in experiments using finite elements in a series of numerical analyses near excavations loaded with a strip footing to investigate reinforced and unreinforced granular soils. The simulation of granular soil behavior is therefore carried out using the hardening soil model (HSM). A couple of closed footings adjacent to the pit were investigated to evaluate the effect of the geogrid reinforcement on their behavior during the response to load. In this research, footing spacing from various granular excavation edges varied with sand excavations $(H=3 B)$. The highest bearing capacity was achieved using various geogrid layers. By utilizing three existing reinforcement layers and increasing the pit setback, it is demonstrated that the final settlement of the footings can be greatly reduced. Based on the findings of this study, the final loading capacity could be increased considerably when three layers of reinforcement are applied to granular soils. Furthermore, the bearing capacity will also increase in a nonlinear manner as the excavation is distanced from its edge. Consequently, it is important to determine the location of the footings carefully. A second advantage is the ability to place foundations adjacently, which increases their bearing capacity and efficiency factor. There is no effect on the effect of interference when the distance between the surface foundations (D) is more than 5 times the foundation width (B).

\section{Introduction}

New buildings are normally built next to old buildings, so this is a more realistic expectation. New excavations and old institutions may interfere with one another as a result. Footings subjected to vertical loads suffer from this interference in terms of bearing capacity, ordinance, and revolution. A particular concern in the vicinity of adjacent excavations is buildings with shallow foundations. The excavation must be augmented during the construction of the new base due to the deeper depth of the new building base than the existing base level of the existing construction. A retaining structure acts as a barrier between belowground utilities and nearby buildings to prevent damage. This means that one of the most important aspects of designing these structures is to enhance the strength of their footings near the edge of the excavation as well as to enhance the load-settlement behavior of these structures. Because excavations can have serious negative impacts on neighboring structures, many researchers have examined how ground movement is affected by excavations. These studies mainly focused on predicting lateral movement and soil regulation related to deep excavation (Peck 1969, Clough and O'Rourke 1990, Ou 1993, Long 2001, Yoo 2001, Wang et al. 2005, Liu et al. 2005, Leung and Ng 2007). Many studies conclude that strengthening the weak soil bed to withstand horizontal shear stresses caused by strip loading and conveying them to the surrounding dense soil mass will improve the settlement characteristics and final bearing capacity of the foundation (Akinmusuru and Akinboladeh 1981, Guido et al. 1986, Khing et al. 1993, Das and Omar 1994, Adams and Collin 1997, Shin et al. 2002, El Sawwaf 2007, Nasr 2014). 
Georgiadis in 2010b assessed the final bearing capacity of the strip footing placed close to the slope through the finite element technique. The findings indicated that monitoring 3 surfaces of failure modes can be performed in terms of the slope height to footing width (H/B) ratio. Shiau et al. in 2011 determined the undrained behavior of strip footing located on a slope over the upper and lower bounds of advanced computer analysis (FELA). Laman and Salih Keskin (2013) conducted an empirical analysis to assess the final bearing capacity of the same type of strip footing over the setback of the granular slope. Their findings showed that by increasing the setback distance, the strip footing's ultimate bearing capacity then incremented. In 2014, Mofidi Rouchi et al, utilized the advanced lower bound technique (FELB) to evaluate the behavior of the strip shape footing close to a slope. Xie and Leshchinsky (2017) using limit analysis (LA) along with discontinuity layout optimization (DLO), computed the carrying pressure of spread shape footing close to cohesive-frictional slopes. In the investigation of Halder et al. (2017), the strip footing carrying capability placed on the granular slope was calculated by advanced FELA analysis. In 2018, Zhou et al, utilized DLO to provide diagrams for the load-settlement behavior of strip loading located on the crest of a slope. The findings proved that the nonlinearity with setback distance increased with the normalize bearing capacity.

Many theories exist regarding the final loading capacity of 2 and 3 interfering strip footings loaded simultaneously with the same loads (Mandel, 1963; Stuart, 1962; Stuart and West, 1965; Amir, 1967; Mogaliah and Siva Reddy, 1976; Khadilkar and Varma, 1977; Patankar and Khadilkar, 1981; Graham, et al. 1984). Utilizing an upper bound limit analysis along with linear and finite element planning, the ultimate bearing capacity of 2 interfering rough strip footings over a cohesion-less medium was calculated by Kouzer and Kumar (2007). Ghosh and Kumar (2007) obtained the bearing capacity of 2 interfering footings utilizing the stress features method. Dash $(1981,1982)$ assessed the problem of determining the final loading capacity of 2 strip footings when the definite load is carried by a nearby footing. Kumar and Kouzer (2010) obtained the footing's ultimate bearing capacity taking into account the interference of a present footing over sand through an upper-bound finite limit analysis. According to these studies, the impact of footing interference is, in general, to cause an increment in the bearing capacity with a reduction in the spacing. Based on the review of the available literature, it can be concluded that the impact of the interference within foundations, particularly near excavation, on the settlement seems to receive little or no consideration. To date, no attention has been given to the problems of interfering strip footings. To date, no rational method exists to evaluate the pressure-settlement characteristics of interfering strip footings adjacent to granular soils. Keeping this in view, the solution to this problem is the aim of this work.

However, very little research was done to calculate the bearing capacity of the embedded footing in the vicinity of an excavation ground by Sawwaf and Nazir 2012. Previous studies referred to above included estimating the highest wall movement, estimating the settlement of the ground surface, its effects on the stimulating foundations of deep piles, and the risk of damage to the nearby building because of the differential settlement (Nasr 2014, El Sawwaf 2012, Aparna and Samadhiya 2019). Nevertheless, as we know, the performance of shallow foundations supported on either unreinforced or reinforced soils near the excavations has not been studied. Consequently, no information exists in the literature on the impact 
of excavations on the performance of strip loading-loaded reinforced soil. Thus, this study mainly aimed to test some important features affecting the behavior of a strip footing over granular soil near an excavation by geogrid reinforcing layers for comprehension of reinforcement mechanisms and recommending an optimum quantity of reinforcements. The parameters that have changed in this study are the distances between the strip footing (width=80 $\mathrm{cm}$ ) and the excavation crest, the number of geogrid layers and the two friction angles.

\section{Material Features}

The hardening soil model was utilized to model the nonlinear performance of sand as an elastic-plastic hyperbolic stress-strain model, formulated into friction hardening plasticity. The footing was very rough and stiff in all the computations explained in this work and the footing settlement was simulated through a uniform prescribed displacement over the sandy layer rather than modeling the footing itself. The soil stiffness stress dependency is a basic property of the hyperbolic model. One of the strengths of PLAXIS software compared to other computer programs is that it can model the soil-structure interaction logically and appropriately. Each contact element is assigned a virtual thickness that is a virtual dimension for defining the properties of the contact material. As the virtual thickness increases, more elastic deformations are produced. In general, contact elements are expected to create very small elastic deformations and, therefore, the virtual thickness must be chosen to be small. Virtual thickness is defined as the coefficient of virtual thickness multiplied by a finite element's average size. The program has a default virtual thickness of 0.1 . The same default value was used in this study. The roughness of the contact surface is modeled by selecting an appropriate reduction factor in the contact surface resistance $\left(R_{\text {inter }}\right)$. This coefficient correlates the contact strength with soil resistance (friction angle and adhesion). Considering the presence of reinforcing elements, the coefficient of soil resistance reduction is considered to be 0.8 for very dense sandy soil (El Sawwaf and Nazir (2010) and Azzam and ElWakil (2016)). Describing the limiting state of stress is performed based on the tangent stiffness modulus of primary compression $E_{\text {ode }}^{50}$, secant Young's modulus $E_{r e f}^{50}$ effective cohesion (c), Poisson's ratio ( $v$ ), soil expansion angle $(\psi)$, interface reduction factor $\left(R_{\text {int }}\right)$, peak soil friction angle $(\phi)$, and failure ratio $\left(R_{f}\right)$. To analyze the soil area, the boundary conditions must be large enough to have the least possible effect on the results. For this purpose, different soil dimensions were analyzed so that the obtained results were not affected by the support conditions. Finally, two-dimensional model dimensions were selected to analyze strip footings of $12.5 \mathrm{~B}=10 \mathrm{~m}$ in the $\mathrm{x}$-direction and $6.25 \mathrm{~B}=5 \mathrm{~m}$ in the $\mathrm{y}$-direction. The boundary circumstances were selected in such a way that at the boundary points of the two ends of the right and sides left of the limited soil, the transfer in the $x$-direction was prevented. Meanwhile, in the $y$-direction, the free transfer was left to show the soil behavior well. This type of support means that the soil is spread in two directions, depending on the model's geometry. Therefore, to show their effect, the displacement is prevented in the $x$-direction, but in the $y$-direction, there is no obstacle in the displacement of the points. Therefore, in this direction, the free transfer is left. At boundary points at the bottom of the soil, the model is limited to bedrock to stabilize it in the $x$ - and $y$-axes. Meshing is done automatically in the PLAXIS software. This was performed by modifying the mesh sizes from coarse to fine based on sensitivity 
analysis (Fig. 1-b). During the PLAXIS procedure, there was no significant difference in the values of applied stress of medium and soft mesh sizes (Ahmad et al. 2020). The number of elements is 1395. Fig. 1-b represents a characteristic arranged numerical model's finite-element mesh for this work. In the initial conditions, the problem is defined in the dry state, and the groundwater level is at the lowest level.

Therefore, there is no pore pressure due to groundwater. After determining the groundwater level, the initial stresses are calculated. In this section, horizontal and vertical stresses are calculated according to the soil weight and the Jackie formula $\left(K_{0}=1-\sin \phi\right)$. In this study, two types of sandy soil were used. The two types of soil were compared only in terms of the friction angle $(\phi)$. Table 1 presents the characteristics of these two types of soil.

Table 1. The soil features utilized in modeling

\begin{tabular}{|c|c|c|c|c|c|c|c|}
\hline Soil & $\begin{array}{c}C^{\prime} \\
\mathrm{kPa}\end{array}$ & $\begin{array}{c}\phi^{\prime} \\
\left(^{\circ}\right)\end{array}$ & $\begin{array}{c}E_{50}^{\text {ref }} \\
\mathrm{MPa}\end{array}$ & $v$ & $\begin{array}{c}\gamma \\
\mathrm{KN} / \mathrm{m}^{3}\end{array}$ & $R_{\text {int }}$ & $\begin{array}{c}D_{r} \\
(\%)\end{array}$ \\
\hline Loose Sand (I) & 2 & 32.2 & 20 & 0.3 & 16.37 & 0.7 & 35 \\
\hline Dense Sand (II) & 1 & 39.4 & 30 & 0.3 & 17.50 & 0.8 & 75 \\
\hline
\end{tabular}

Table 2. The mechanical and physical features of reinforcement

\begin{tabular}{|c|c|}
\hline Structure & Biaxial geogrid \\
\hline Aperture shape & Rectangular apertures \\
\hline $\begin{array}{c}\text { The size of Aperture, } \\
\text { mm x mm }\end{array}$ & $42 \times 50$ \\
\hline Polymer kind & Polypropylene \\
\hline Weight, gr/m2 & 180.0 \\
\hline $\begin{array}{c}\text { Tensile strength at 2\% } \\
\text { strain, KN/m }\end{array}$ & 4.4 \\
\hline $\begin{array}{c}\text { Tensile strength at } 5 \% \\
\text { strain, KN/m }\end{array}$ & 13.5 \\
\hline $\begin{array}{c}\text { At a peak tensile } \\
\text { strength KN/m }\end{array}$ & 180.0 \\
\hline $\begin{array}{c}\text { Tensile stiffness EA, } \\
\mathrm{KN} / \mathrm{m}\end{array}$ & \\
\hline
\end{tabular}

Elastic "geotextile elements" were used to model the geosynthetic reinforcement. The reinforcing material was a kind of geogrid with an axial stiffness of $180.0 \mathrm{kN} / \mathrm{m}$ for the numerical modeling. The mechanical and physical features of the reinforcement are presented in Table 2.

Table 3. Geometric characteristics of the sheet pile wall

\begin{tabular}{|c|c|c|c|}
\hline & $\mathrm{EA}(\mathrm{KN} / \mathrm{m})$ & $\mathrm{EI}\left(\mathrm{KN} \cdot \mathrm{m}^{2} / \mathrm{m}\right)$ & Thickness $(\mathrm{mm})$ \\
\hline Sheet pile Wall & $42 \times 10^{6}$ & $14 \times 10^{4}$ & 20 \\
\hline
\end{tabular}


In this research, plate elements were used as a sheet pile. As mentioned earlier, defining a plate element requires axial stiffness and bending stiffness to define the steel shield. Some geometric features of this shield are presented in Table 3.

\section{Verification And Finite Element Analysis}

The scope of this work was modeled and investigated using 2D finite element analysis (FEA) over a prototype footing-excavation system to verify the laboratory model test outcomes in a previous study (El Sawwaf and Nazir 2012) and to understand that the strip footing performance was located on the reinforced and unreinforced granular soils adjacent to the excavation. PLAXIS can handle various geotechnical problems, such as tunnels, deep excavations, and earth structures, such as slopes and retaining walls. The soil mass modeled through PLAXIS software possessing the same dimensions was used in previous studies (El Sawwaf and Nazir 2012) and is $10 \mathrm{~m} \times 5 \mathrm{~m}$ in the plan, $\mathrm{B}=0.80 \mathrm{~m}$, in which $B$ represents the strip footing width containing an excavation with height $\mathrm{H}=3 \mathrm{~B}=2.4 \mathrm{~m}$ in a corner. The setback between the edges of excavation and footing $(b)$ denotes a variable parameter and footing width $B$, as well as the geosynthetic layers.

It was hypothesized that in all FEM analyses, the adopted soil parameters remain the same for the unreinforced system. A reinforcement layer was inserted in the reinforced case at the needed embedment with proper strength decrease parameters, after which another planar geogrid sheet was added. The program was reanalyzed, and ultimately, the 3rd geogrid planar sheet was inserted, and the analysis was again performed. It was assumed that the distance between the reinforcing layers, embedment of the first layer of the geogrid and the reinforcement length were always constant at $x / B=0.6, u / B=0.3$ and $L / B=5$, respectively.

To ensure the findings of the PLAXIS software and compare the finite element technique results with the experimental findings (El Sawwaf and Nazir 2012), first, a nonreinforced dense sand mass was modeled $\left(\phi=39.4^{\circ}\right)$ without any excavation, and then a comparison was made for the ultimate bearing capacities. Second, a reinforced dense sand mass $\left(\phi=39.4^{\circ}\right)$ was modeled with a reinforcement layer with no excavation to compare the ultimate bearing capacity. Fig. 2 presents the load-settlement curve obtained from the two-dimensional numerical model and the results of the physical model for the footing mode located on the nonreinforced dense sand without the excavation. In this case, two constitutive models of soil were used to calibrate the numerical model. The soil numerical behavioral models are HSM and Mohr-Coulomb (MC).

Figure 2 shows that the bearing capacity attained from the empirical model (El Sawwaf and Nazir 2012) is consistent with the results of the hardening soil model, but the difference in the Mohr-Coulomb model is relatively large. As (Fig. 3) clearly shows that for reinforced granular soil, there is good consistency between the experimental results (El Sawwaf and Nazir 2012) and the finite element model results.

From the test models, the load-settlement curves were acquired. The following technique was utilized to calculate the final bearing capacity since no certain failure point was found on the load-settlement 
diagrams. For this purpose, after drawing the plot, two tangents are drawn, i.e., the first tangent to the first part of the diagram and the second tangent to the end part of the diagram. The intersection of these two tangents determines the ultimate bearing capacity of the surface foundation (Vesic 1973), as shown in Fig. 4.

\section{Results And Discussions}

In this section, the obtained results are examined and discussed. First, how to calculate the final bearing capacity of surface foundations is discussed. Next, the initial two-dimensional analysis of the strip foundation in the direction parallel to the pit is examined. Finally, the preliminary results of the initial analysis of unreinforced and reinforced soil were compared.

The final bearing capacity of reinforced granular soil can be considered as a function of these parameters as follows:

$$
\frac{P_{u}}{\gamma B}=f\left(\frac{H}{B}, \frac{b}{B}, N, \phi, \frac{L}{B}, \frac{u}{B}, \frac{h}{B}, \frac{s}{B}, \frac{\Delta}{H}, \frac{\Delta}{B}, B C R, \frac{D}{B}\right)
$$

where $(\mathrm{H})$ denotes the excavation depth, (b) represents "the setback from the edge" of an excavation, $(\mathrm{N})$ represents the number of "geogrid layers", (BCR) describes the "bearing capacity" ratio, $(\varphi)$ is the "friction angle", (L) is the length of reinforcement, (u) is the burial depth of the first "geogrid layer", (h) denotes the vertical spacing between geogrid layers, (s) is the footing settlement, (B) is the footing width, (D) denotes the spacing between two footings, and $(\Delta)$ is the deflection of the "sheet pile wall". Some numerical analysis tests were carried out for eight various edge distances of the footing on both cases reinforced and unreinforced sandy soils near the excavation with embedment depth $(H / B=3)$, corresponding to $b / B=0,1.0$, into... 8.0 for two types of granular soils.

The distance between the geogrid layers is considered to be equal to $h / B=0.6$, and the distance of the first geogrid to the ground level equal to $u / B=0.3$ is constant. The length of the reinforcements is also large enough to not affect the load-bearing capacity of the surface foundations. The ratio of the length of the reinforcer to the width of the foundation is equal to $L / B=5$, which is $L$ the length of the reinforcing.

\subsection{The impact of footing location related to the excavation}

In this work, to identify the impact of the vicinity of a footing to the excavation (b/B) on bearing capacity, some numerical analyses were carried out for eight various edge distances of the footing on the unreinforced and reinforced sandy soils near the excavation $(\mathrm{H}=3 \mathrm{~B})$, corresponding to $b / B=0,1.0$, into...

8.0. The alterations in final bearing capacity (stated as a nondimensional ratio $P_{u} / \gamma B$, in which $P_{u}$ shows the final bearing capacity and $y$ represents the soil's unit weight) at various setbacks for unreinforced sandy soil are provided in Figure 5. The findings show that in unreinforced loose sandy soil, the final bearing capacity increases with increasing setbacks. Within a setback of $8 B$, a footing's final bearing 
capacity over the unreinforced loose sandy ground is the same for a footing over a level surface. Locating the footing within an edge distance over 8-fold minimizes the impact of excavation.

As the $\mathrm{b} / \mathrm{B}$ ratio increases, the effect on the foundation final load capacity decreases. This can be seen by looking at the effect of deformation and the overall displacements resulting from the foundation load in the vicinity of the pit, as well as the effect of the distance from the pit on the distribution and expansion of the main stresses underneath the strip foundation, as shown in Fig. 6. Similarly, by controlling the hardening points of the modulus plastic, the impact of the distance from the pit on the final load capacity of the foundation can be examined, as indicated in Fig. 7. The solid dots in Fig. 7 represent the points at which the stress has reached the plastic state, according to the hardening rupture criterion (HSM). The solid black dots also indicate a rupture due to tensile stresses. Grounded in this basic concept that the soil cannot transmit tensile stresses, tensile fractures occur. These types of points that are under tension are often created close to the surface and due to the displacement of the pit wall, where the strength is low.

\subsection{Effect of one reinforcement layer}

The second set of numerical examinations was conducted for eight various setbacks of the footing over a one-geogrid layer, equivalent to $(D / B=0-8)$. Figure 8 shows the changes in final bearing capacity at various setbacks. The results in this figure present that at any given edge distance, for inclusion of a onegeogrid layer, the final bearing capacity of a strip footing over reinforced loose sand near excavation is greater compared to a footing on unreinforced loose sand, but this increase in bearing capacity of loose sand for one layer of geogrid is not great, thus reflecting the weak efficiency of one layer of geogrid in enhancing the bearing capacity of the footing nearby an excavation.

From the results of numerical analysis, it is concluded that the inclusion of one reinforcing layer improves the physical and mechanical features of granular soil, and placing one reinforcing layer in loose sandy soil with low density is more effective than placing one reinforcing layer in dense sandy soil. Due to this, the stiffness of loose sandy soil improves, and this soil becomes denser. As a result, its shear strength increases. The reinforcement does not have much effect on the specifications of dense sandy soil. It will be explained in the next sections.

\subsection{The impact of the number of reinforcing layers}

The third set of numerical examinations was carried out for eight various setbacks of the footing over a multilayered reinforcing, equivalent to $D / B=0-8$. The changes in the final bearing capacity at various setbacks are represented in Figure 9. For comparison, bearing capacity ratio (BCR) parameters were inserted corresponding to the ratio of the reinforced footing bearing capacity to the nonreinforced footing bearing capacity. Figure 10 shows the results based on this parameter.

It is indicated that utilizing more than a reinforcement layer significantly increases the ultimate bearing capacity. This increase in bearing capacity by using three-layer reinforcement is great in comparison to 1 
or 2 layers. This result is in contrast with all the results regarding reinforcing sandy soils with sand cushion reinforcement or a reinforced sand layer. Moreover, this is caused by the decrease in plastic points created between layers in confined soil. Therefore, it reflects the advantageous impact of reinforcement in enhancing the bearing capacity of one strip footing near excavation. Moreover, utilizing a three-layer reinforcing, the final bearing capacity of one strip footing equivalent to $b / B=5$ is the same for a footing on a nonreinforced level surface. These variations in the final bearing capacity of the footing with excavation can be clarified by incrementing the passive earth pressure with incrementing the setback from the excavation. Further passive pressure results in a deeper and wider failure zone; thus, the bearing capacity increases.

The outcome in Fig. 10 indicates that the BCR increments by increasing the layer reinforcement, and the results of a finite element represent the bearing capacity ratio of one strip footing increments by utilizing a sheet pile wall. As a result, the stability of reinforced loose sand near the excavation sandy increases when using three layers of reinforcement and a sheet pile wall. The strip footing's final load-bearing capacity increments by incrementing the setback between the footing and sheet pile wall, $b / B$, and the impact of deep excavation decreases.

As shown in Fig. 10, near the excavation and in contact with it, increasing the number of reinforcing layers increases the final load-bearing capacity of the foundation. In the case of contact with the pit, the final load capacity increases by approximately $38 \%$ with one reinforcing layer. Additionally, by using two reinforcing layers, the final loading capacity increased by approximately $73 \%$, and by placing three reinforcing layers, the capacity value increased. The final loading increases by approximately $204 \%$. Therefore, to use the maximum performance of the reinforcing layer, it is recommended to use three layers of geogrid in contact with the pit. The reason for this is the creation of high-hardness plates, in which the loose sandy soil at our distance between them becomes denser due to the increment in density and the reduction in the porosity ratio of the granular soil. The reason for this is that placing the reinforcing layer of main and effective stresses between the hard plates in which the particles of soil will be rearranged will increase the relative density of the reinforced grain soil and reduce its porosity ratio and soil density. The frictional forces between particles of soil will be increased; consequently, the resistance of the soil is greatly increased.

As shown in Fig. 11, increasing the number of reinforcing layers causes much hardness, among which layers of loose sand are placed, which causes the number to increase. The fewest points in a distance away from the edge of the pit can reach the plastic state, but in contact with the pit, the number of plastic points is greater, and the failure of soil has occurred under the tension stress effect, so increasing the reinforcing layers has a very positive effect on the final loading capacity. In addition, depends on the H/B depth ratio. When the magnitude of the setback ratio reaches $b / B=0-5$, the number of reinforcing layers is three, and after this value $b / B>5$, one reinforcing layer is required.

If a designer wants to design a strip foundation adjacent to the excavation using three reinforcing layers and place the foundation strip at a distance from the pit, the final loading capacity equals the final 
loading capacity of the foundation on the same unreinforced soil, and by neglecting the affected depth of the pit, it can place a strip of tape at a certain distance from the side of the pit, depending on the depth of the pit. For a depth ratio of $H / B=1$, the appropriate distance equals $b=2 B$; for $H / B=2$, the appropriate distance is equal to $b=5 B$; and for a depth ratio of $H / B=3$, the suitable distance is equal to $b=6 B$. For example, considering the ratio of the depth of the pit $\mathrm{H} / \mathrm{B}=3$, the normalized final loading capacity without the use of a geogrid and without the impact of the depth of the pit according to Fig. 9 is approximately equal to 50 . To achieve this load capacity using three reinforcing layers, according to Fig. 9, the strip foundation should be placed at a distance of $b=6 \mathrm{~B}$. As expected, given the depth of the excavation, the strip foundation should be placed at a greater distance from the pit.

\subsection{The impact of friction angle, $\Phi^{\prime}$}

To study the impact of the friction angle on the final loading capacity of reinforced sandy soils adjacent to an excavation, a set of examinations was conducted with the same circumstances as other tests, and only an alteration occurred in the friction angle, $\Phi$, of the soil to $39.4^{\circ}$. The findings are provided in Figs. 12-14.

In Fig. 12, the two curves show that in unreinforced soils, the final loading capacity increases by rising the effective friction angle from $32.2^{\circ}$ to $39.4^{\circ}$. As in loose sand, the final loading capacity of dense sand increases by raising the setback. Within a setback of $8 B$, the final loading capacity of a footing over an unreinforced dense sand ground is the same for a footing over a level surface.

According to Figure 13, regarding the soils reinforced with geosynthetic reinforcement, the strip footing's ultimate bearing capacity will be increased by increasing the friction angle. It is clarified by the Hardening Soil Model criterion. Based on this criterion, by increasing the effective friction angle $\Phi^{\prime}$ of the soil, the plastic volumetric strain is small, the stresses built up between the sheet soil mass are rearranged, and by rising the geogrid layers, interlocking and the contact area between the soil and geosynthetic layers increase. Therefore, a resistance was created against larger horizontal shear stresses and soil displacements created in the soil under the footing, and they were conveyed via geogrid layers to a larger soil mass. Thus, the failure wedge extends and makes the frictional resistance over the failure planes larger (El Sawwaf and Nazir 2012).

Normal changes in BCR measured from numerical modeling against the geosynthetic layers are represented in Figure 14. The BCR was further enhanced with the number of geosynthetic layers of dense sandy soils. The curves represent a significant increase in the BCR by incrementing the number of geosynthetic layers until $\mathrm{N}=3$; then, the load improvement rate is much lower. At a distance larger than 3 times the footing width of the sheet pile wall, the footing bearing capacity with a 3 layer geogrid increases by $85 \%$ in comparison to the unreinforced sand soil.

\subsection{Effect of settlement}


The reinforcing effectiveness on footing foundation settlement is assessed. Figure 4 represents the settlement method determined by the load-settlement curve. Table 4 provides the changes in the final loading capacity and footing settlement for $b / B=0$ and $\Phi=32.2^{\circ}$.

Table 4

The results of $b / B=0$ and $\phi^{\prime}=32.2^{\circ}$

\begin{tabular}{|lll|}
\hline Soil & $\begin{array}{l}\text { Bearing } \\
\text { Capacity (Pu/YB) }\end{array}$ & Settlement ratio (S/B\%) \\
\hline Unreinforced & 15.30 & 1.38 \\
\hline 1-layer reinforcement & 15.75 & 1.1 \\
\hline 2-layer reinforcement & 22.00 & 1.5 \\
\hline 3-layer reinforcement & 26.00 & 2.19 \\
\hline
\end{tabular}

According to Table 4, foundation settlement increases with reinforcing; however, using a three-layer reinforcement appears logical when incrementing the final loading capacity, and permissible amounts of the settlement are taken into account. Regarding other locations, it is not essential to use reinforcing to increase footing settlement and decrease the final loading capacity. For instance, the loading capacity of a soil bed with three layers of reinforcement is higher than that of unreinforced soil. However, the settlement was incremented for three-layer reinforcing as a result of tension rupture of the soil confined between geogrid layers. Sandy soil assessments are carried out for denser soil with a greater range of friction angles $\left(\Phi^{\prime}=39.4^{\circ}\right)$, and the findings are provided in Table 5.

Table 5

The changes in bearing capacity and footing settlement for $b / B=0$ and $\phi=39.4^{\circ}$

\begin{tabular}{|lll|}
\hline Soil type & $\begin{array}{l}\text { Bearing } \\
\text { Capacity (Pu/YB) }\end{array}$ & Settlement ratio (S/B\%) \\
\hline Unreinforced & 20.09 & 0.75 \\
\hline 1-layer reinforcement & 22.00 & 1.00 \\
\hline 2-layer reinforcement & 25.00 & 1.20 \\
\hline 3-layer reinforcement & 27.14 & 1.50 \\
\hline
\end{tabular}

By comparing Tables 4 and 5 , it is indicated that these two kinds of soil have similar results. Hence, it is very advantageous to use reinforcement in sandy soil with a high friction angle due to the increased final 
loading capacity. Figure 15 shows the changes in the settlement ratio $S / B$ to the footing places b/B. Moving the footing away from the excavation, a reduction occurs in the excavation impact. Nevertheless, the impact of excavation on the footing performance is obvious for $b / B=5$, which then can be regarded as constant. Furthermore, it is observed that by reinforcing the soil in dense sands, a larger impact occurs on the footing performance for the footing near the excavation.

\subsection{Effect of internal strip foundation}

In this section, the effect of having an internal strip foundation and the effect of extending and connecting the reinforcements under these two strip footings on the stability and final loading capacity of the grain soil are examined. In this part, the width of the closely spaced strip foundations is the same, (D) is the distance between two adjacent strip foundations, and the buried depth of the foundations is zero. The same external load is the same on the two adjacent strip foundations. First, adjacent strip foundations are considered on unreinforced granular soil. In this section, $\mathrm{I}_{f}$ (interference factor), the interference coefficient is defined as follows:

$$
I_{f}=\frac{P_{u(\text { int }-r e)}}{P_{u(\text { single }- \text { unre })}}(2)
$$

in which $\mathrm{Pu}_{(\mathrm{int}-\mathrm{re})}$ is the final loading capacity of the interlocking foundation based on reinforced granular soil and $\mathrm{Pu}_{\text {(single-unre) }}$ is the final loading capacity of the single foundation based on unreinforced granular soil.

The parameters used in this section are the distance from the setback of the pit $b / B=0$ and in the case of unreinforced and reinforced soil with continuous reinforcing layers $N=1,2,3$, and the ratio of different depth depths $H / B=3$ is considered. Additionally, in this section, the geogrid length is increased by moving the distance (D) between the two sides of the strip, for example, $L / B=5,6,7,8,9,10$. The ratio of the distances between footings to the width of the footings $D / B$ is considered, and the distance (D) is assumed to be equal to the distance from the container to the container of the sides. When the foundations do not affect each other, the coefficient of interference will be equal to one.

According to the results of Figures (16) and (17), the placement of the foundations close to each other increases the load-bearing capacity and their efficiency. Figures (16) to (19) show that at low values of the distance ratio between adjacent foundations and based on reinforced soil, the loading capacity is due to the impact of slippery wedges and the tolerance of some loads by the reinforcer. Has increased, and this increase in armed mode is significant in the three layers of the geogrid. As the depth of excavation increases and the number of continuous reinforcing layers increases, the efficiency of adjacent foundations also increases. The efficiency of adjacent strip foundations in terms of load capacity to distance $(D=3 B)$ shows an increasing trend; in such a way that this range can be considered as the distance between two peeps in a single width $\left(\left(\left(B_{1}+B_{2}\right) / 2\right)+D\right)$. By incrementing the distance between the strip foundations, the load capacity and their effect on each other are reduced. As a result of the presence of continuous reinforcements, the final loading capacity of the interconnected strip foundations 
increases, its amount increments by the larger distance of the foundations (D), and the interference coefficient $\left(l_{f}\right)$ increases by more than one. To determine the length of the continuous reinforcing layer, considering that the coefficient of interference of the foundations, the strip, and the optimal number of reinforcing layers is three $(\mathrm{N}=3)$, shape (17) can be used. If a designer wants to calculate the length of the reinforcing layers, the length of the reinforcing layer can be obtained by subtracting the value of the coefficient of interference from Fig. 16 and using the results of Fig. 17.

The main reason for increasing the final loading capacity of adjacent strip foundations is that by increasing the distance between the foundations to the extent that the rupture interference surface does not have much effect, the coefficient of interference decreases, and in close conditions, the individual reinforced foundation conditions are established. In the case of the interference coefficient $\left(I_{f}\right)$, since in the close distances of the foundations, the rupture surface of the adjacent resistant area of the foundation passes through the active area of the desired foundation, and the number of plastic points in the area between the strip foundations decreases. By the larger the distance of the strip foundations from the level of rupture of the adjacent resistant area of the adjacent foundation, gradually the active strip of the desired strip is removed, and as a result, the plastic points in the area between the adjacent strip foundations, the resistant force of the interlocking wedges and the resistance of the reinforcing friction lead to increase the coefficient of interference of the base strips resting on loose reinforced granular soil $\left(I_{f}\right)$, as indicated in Figures (18) and (19).

Figures (16) and (17) show that the coefficient of interference of strip foundations based on reinforced granular soil depends on the distance between the foundations and the number and length of continuous reinforcing layers. For loose sandy soils, the geogrid is reinforced with three layers, and the depth of the pit is $\mathrm{H}=3 \mathrm{~B}$. The interference coefficient is in the range of 4.10 to 5.55 for the distances between the footings $D=(1-3) B$. The length of the geogrid in these cases is approximately $L=(5-10) B$. In addition, these figures demonstrate that in the distance ratio beyond 6 times the width of the foundation $(D>6 B)$, the effect of interference can be neglected, and each of the strip foundations behaves as a single foundation.

If the general load equation includes the coefficient of interference $\left(I_{f}\right)$, its modified form for the surface foundation of the strip based resting on noncohesive granular soil $(\mathrm{c}=0)$ and the depth of the strip foundation $\left(D_{f}=0\right)$ will be written utilizing a modified Terzaghi's equation (Terzaghi, 1943) as follows:

$$
\frac{P_{u}}{\gamma B}=\frac{1}{2} N_{\gamma} I_{\gamma s} I_{\gamma d} I_{\gamma i} I_{\gamma g} I_{\gamma b} I_{f}(3)
$$

Concerning Equation (3), $N_{\gamma}$ is the load capacity coefficient, $I_{\gamma s}$ is the foundation shape coefficient, $I_{y d}$ is the foundation depth factor, $I_{\gamma i}$ is the slope load factor, $I_{\gamma g}$ denotes the slope ground factor, $I_{\gamma b}$ is the setback factor, and $l_{f}$ is the footing interference coefficient. For interference strip footing rest at $D_{f}=0$ and the applied load is in the center of the footing, these coefficient values $\left(I_{y s}=I_{y d}=I_{y i}=1\right)$ are equal to one. However, the slope ground factor can be expressed as $\left(I_{\gamma g}=(1-m \tan \phi)^{n}\right)$, in which $\mathrm{m}=0.5$ and $\mathrm{n}=5$ 
were suggested by Hansen (1970) and $m=1$ and $n=2$ were suggested by Vesic (1975). Based on the results of an analytical study using the rigorous Janbu's slice method, Huang and Kang (2008b) suggested that parameters $m$ and $n$ are functions of $\varphi$ or $\beta$, expressed as Huang (2019):

$$
m=1.062-0.014 \times \phi\left({ }^{\circ}\right), \text { andn }=\frac{\beta\left({ }^{\circ}\right)}{10}=\frac{90}{10}=9(4)
$$

Based on this study, the setback correction factor $\left(\mathrm{I}_{\mathrm{\gamma b}}\right)$ for the final bearing capacity of a surface footing placed at the crest of a pit with a setback (b) can be derived using Fig. 9 and Fig. 13. These figures show that as $\mathrm{b} / \mathrm{B}$ increases to a threshold value of $(\mathrm{b} / \mathrm{B})_{\mathrm{C}}$, the final bearing capacity of the footing is equal to that of a footing placed on horizontal ground. The values for the setback factor $\left(I_{y b}\right)$ are found to be functions of $b / B$ and $\varphi$, where $\beta=90^{\circ}$. The following correction factors $\left(I_{\gamma b}\right)$ can be proposed for the setback of a footing situated near a pit:

For $b / B<(b / B)_{c}$, then

For loose sand, $\varphi=32.2^{\circ}, \mathrm{I}_{\mathrm{yb}}=0.13 \mathrm{~b}+0.2$.

For dense sand, $\varphi=39.4^{\circ}, \mathrm{I}_{\mathrm{\gamma b}}=0.14 \mathrm{~b}+0.24$.

For $b / B>(b / B)_{c}$, the pit's effect is dissipated.

where $b$ is the footing setback from the crest of the pit. The pits' depth has not affected this factor.

Then, Equation 3 becomes as follows:

$$
\frac{P_{u}}{\gamma B}=\frac{1}{2} N_{\gamma} I_{\gamma g} I_{\gamma b} I_{f}(5
$$

\section{Conclusions}

The effect of excavation with $\mathrm{H}=3 \mathrm{~B}$ on the performance of nearby shallow strip footings over reinforced and nonreinforced sands was modeled and investigated. According to the numerical analysis, it is concluded that reinforcing the soil in granular soil under a strip footing near the excavation significantly increases the ultimate bearing capacity of the footing, and higher stability is provided to the footing. By increasing the setback of $0-8 B$, the final loading capacity of the footing on reinforced and unreinforced slopes is increased. Nevertheless, at a setback higher than $8 B$, the footing's final loading capacity does not seem to be influenced by the excavation. Utilizing a three-layer reinforcement, a footing's ultimate bearing capacity of $b / B=5$ is similar to a footing on a nonreinforced level surface. The greater advantages are caused by reinforcing the soil in denser sand with a greater footing load value. Despite the unreinforced soils, the ultimate bearing capacity increases by a larger friction angle in reinforced soils as a result of creating more tension failure points by increasing the shrinkage in the failure surface and 
effective friction angle $\Phi$. In granular soils, the bearing capacity increases by increasing the reinforced layer. The increased settlement of the footing can remove this good impact when this settlement is in the allowable value of the footing settlement. The optimum number of reinforcement layers is three, which increases the final loading capacity of the strip footing on the reinforced granular soils adjacent to excavation.

In loose and dense granular soils, the placement of foundations adjacent to each other increases their bearing capacity and efficiency. As the depth of excavation increases and the number and length of continuous reinforcing layers increase, the efficiency of adjacent surface foundations also increases. As a result of the presence of continuous reinforcements, the load-bearing capacity of the interfering surface foundations increases, its amount increases with increasing distance of the surface foundations (D), and the interference coefficient $\left(I_{f}\right)$ increases by more than one. It can be concluded that the use of continuous reinforcements under adjacent surface foundations also improves the strength of granular soils and increases the stability of adjacent surface foundations. In the ratio of the distances between the surface foundations beyond 5 times the foundation width $(D>5 B)$, the effect of interference is negligible, and each of the surface foundations acts as a single foundation.

\section{Declarations}

The authors have no conflicts of interest to declare that they are relevant to the content of this article.

No funding was received for conducting this study.

\section{References}

Adams M, Collin J (1997). Large model spread footing load tests on geosynthetic reinforced soil foundations. J Geotech Geoenviron Eng, 123(1), 66-72.

Ahmad H, Mahboubi A, Noorzad A (2020). Scale effect study on the modulus of subgrade reaction of geogrid-reinforced soil. SN Appl. SCl., 2(4), 394. https://doi.org/10.1007/s42452-020-2150-4

Akinmusuru JO, Akinboladeh JA (1981). Stability of loaded footings on reinforced soil. J Geotech Eng Div ASCE, 107(6), 819-27.

Amir JM (1967). Interaction of adjacent footings. Proc. 3rd Asian Regional Conf. On Soil Mechanics and Foundation Engineering, Haifa: 1(5): 189-192.

Aparna, Samadhiya NK (2019). Evaluation of model sheet pile wall adjacent to a strip footing-an experimental investigation. International Journal of Geotechnical Engineering, 1-8.

Beyg M, Keshavarz A, Abbaspour M, Vali R, Saberian M, Li J (2020). Finite element limit analysis of the seismic bearing capacity of strip footing adjacent to excavation in $\mathrm{c}-\varphi$ soil. Geomechanics and Geoengineering, 1-14. 
Brinkgreve RBJ, Broere W, Waterman D (2004). Plaxis-finite element code for soil and rock analysis. Version 8.2 Plaxis BV, The Netherlands.

Clough GW, O'Rourke TD (1990). Construction induced movements of in situ walls. In: Proceedings of the design and performance of earth retaining structures. Geotechnical Special Publication, vol. 25, no. 4. New York: ASCE, 390-470.

Das BM, Omar MT (1994). The effects of foundation width on model tests for the bearing capacity of sand with geogrid reinforcement. Geotech Geol Eng, 12:133-41.

Das BM, Labri-Cherif S (1983). Bearing capacity of two closely spaced shallow foundations on sand. Soils and Foundation, Japanese Society of Soil Mechanics and Foundation Engrg, 23 (1): 1-7.

Deshmukh AM (1979). Interference of different types of footings on sand. Indian Geotech. J, 8 (4): 193204.

El Sawwaf M (2007). The behavior of strip footing on geogrid-reinforced sand over a soft clay slope. Geotext Geomembranes, 25 (1): 50-60.

El Sawwaf M, Nazir KA (2012). The effect of deep excavation-induced lateral soil movements on the behavior of strip footing supported on reinforced sand. Journal of Advanced Research, 3: 337-344.

El Sawwaf M, Nazir AK (2010). Behavior of repeatedly loaded rectangular footings resting on reinforced sand. Alexandria Engineering Journal, 49 (4), 349-356.

Georgiadis K (2010). Undrained bearing capacity of strip footings on slopes. Journal of Geotechnical and Geoenvironmental Engineering, 136(5), 677-685. Doi: 10.1061/(ASCE) GT.1943-5606.0000269.

Graham J, Raymond GP, Supplah A (1984). Bearing capacity of three closely spaced footings on sand. Geotechnique, 34 (2): 173-182.

Guido VA, Chang DK, Sweeney MA (1986). Comparison of geogrid and geotextile reinforced earth slabs. Can Geotech J, 23:435-40.

Halder K, Chakraborty D, Kumar Dash S (2017). Bearing capacity of a strip footing situated on soil slope using a nonassociated flow rule in lower bound limit analysis. International Journal of Geotechnical Engineering, 1-9. DOI: 10.1080/19386362.2017.1325119.

Huang CC, Kang WW (2008a). The effect of a setback on the bearing capacity of a surface footing near a slope. J. Georg. 3 (1), 25-32.

Huang CC, Tatsuoka F, Sato Y (1994). Failure mechanisms of reinforced sand sloped loaded with a footing. Soils Found. 34 (2), 27-40. 
Huang CC (2019). Effects of restraining conditions on the bearing capacity of footings near slopes. Soils Found. 59 (8), 1-12.

Khadilkar BS, Varma (1977). Analysis of interference of strip footings by FEM. Proc. 9th Int. Conf. on Soil Mechanics and Foundation Engrg, Tokyo: Japan, 1: 597-600.

Khing KH, Das BM, Puri VK, Cook EE, Yen SC (1993). The bearing capacity of a strip foundation on geogrid-reinforced sand. Geotextiles and Geomembranes, 12(4), 351-361.

Kouzer KM, Kumar J (2008). Ultimate bearing capacity of equally spaced multiple strip footings on cohesion-less soils without surcharge. International Journal for Numerical and Analytical Methods in Geomechanics, 32 (11): 1417-1426.

Kouzer KM, Kumar J (2010). Ultimate bearing capacity of a footing considering the interference of an existing footing on sand. Geotech and Geol Eng, 28(4): 457-470.

Kumar J, Ghosh P (2007). Ultimate Bearing Capacity of Two Interfering Rough Strip Footings. Int. J. Geomech, 7 (1): 53-62.

Leshchinsky B, Xie Y (2017). Bearing capacity for spread footings placed near C- $\Phi$ slopes. Journal of Geotechnical and Geoenvironmental Engineering, 143 (1): 0601-6020. DOI: 10.1061/(ASCE) GT.19435606.0001578 .

Leung HY, Ng CW (2007). Wall and ground movements associated with deep excavations supported by cast in situ wall in mixed ground conditions. J Geotech Geoenviron Eng, 133(2):129-43.

Liu GB, Ng CW, Wang ZW (2005). Observed performance of a deep multistrutted excavation in Shanghai soft clays. J Geotech Geoenviron Eng, 31(8):1004-13.

Long M (2001). Database for retaining wall and ground movements due to deep excavations. J Geotech Geoenviron Eng, 127(3):203-24.

Mandel J (1963). Interaction plastique de foundations superficielles. Proc. Int. Conf. on Soil Mechanics and Foundation Engrg, Budapest. 267-270.

Mofidi Rouchi J, Farzaneh O, Askari F (2014). Bearing capacity of strip footings near slopes using lower bound limit analysis. Civil Engineering Infrastructures Journal, 47 (1): 89-109. DOI:

10.7508/CEIJ.2014.01.007.

Meyerhof GG (1957). The ultimate bearing capacity of foundations on slopes. In: Proc. 4th ICSMFE, London, vol. 1, pp. 384-386.

Meyerhof GG (1963). Some recent research on the bearing capacity of foundations. Can. Geotech. J. 1 (1), 16-26. 
Nadaf MB, Mandal JN (2017). Numerical Analyses of Loaded Strip Footing Resting on Cellular Mattress and Strips: Reinforced Fly Ash Slope. International Journal of Geosynthetics and Ground Engineering, 3 (3): 26.

Naeini SA, Rabe BK, Mahmoodi E (2012). Bearing capacity and settlement of strip footing on geosynthetic reinforced clayey slopes. Journal of Central South University, 19 (4): 1116-1124.

Nasr AM (2014). Behavior of strip footing on fiber-reinforced cemented sand adjacent to sheet pile wall. Geotextiles and geomembranes, 42 (6): 599-610.

Ou CY, Hsieh PG, Chiou DC (1993). Characteristics of ground surface settlement during excavation. Can Geotech, 30: 758-67.

Peck RB (1969). Deep excavations and tunnelling in soft ground. State of the art report. In: Proceedings of the 7th international conference on soil mechanics found engineering, Mexico. 225-90.

Saran S, Agarwal VC (1974). Interference of surface footings in sand. Indian Geotech. J, 4 (2): 129-139.

Salih Keskin M, Laman M (2013). Model studies of bearing capacity of strip footing on sand slope. KSCE Journal of Civil Engineering, 17 (4): 699-711. doi:10.1007/s12205-013-0406-x.

Shiau JS, Merifield RS, Lyamin AV, Sloan SW (2011). Undrained stability of footings on slopes. International Journal of Geomechanics, 11(5), 381-390.

Shin EC, Das BM, Lee ES, Atalar C (2002). Bearing capacity of strip foundation on geogrid-reinforced sand. Geotechnical \& Geological Engineering, 20(2), 169-180.

Siva Reddy A, Mogallah G (1976). Interference between surface strip foundations on soil exhibiting anisotropy and nonhomogeneity in cohesion. J. Inst. of Engrs, 57: 7-13.

Stuart JG (1962). Interference between foundations with special reference to surface footings in sand. Geotechnique, 12 (1): 15-23.

Terzaghi K (1943). Theoretical Soil Mechanics. Wiley, New York.

Vesic AS (1969). Bearing Capacity of Shallow Foundations Foundation Engineering Handbook Chapter 3. Springer, pp. 121-147.

Vesic AS (1973). Analysis of ultimate loads of shallow foundations. J Soil Mech Found Div, ASCE, 94 (3): 661-88.

Vesic AS, Winterkorn HF, Fang HY (1975). Foundation Engineering HandbookFoundation Engineering Handbook Chap. 3, first ed. Van Nostrand Reinhold, New York, p. 751. 
Wang ZW, Ng CW, Liu GB (2005). Characteristics of wall deflections and ground surface settlements in Shanghai. Can Geotech J, 42 (5): 1243-54.

Yoo C (2001). Behavior of braced and anchored walls in soils overlying rock. J Geotech Geoenviron Eng, 127(3):225-33.

Zhou H, Zheng G, Yin X, Jia R, Yang X (2018). The bearing capacity and failure mechanism of a vertically loaded strip footing placed on the top of slopes. Computers and Geotechnics, 94, 12-21.

\section{Figures}

\section{Figure 1}

a) FE modeling of the geometric system and b) mesh size analysis

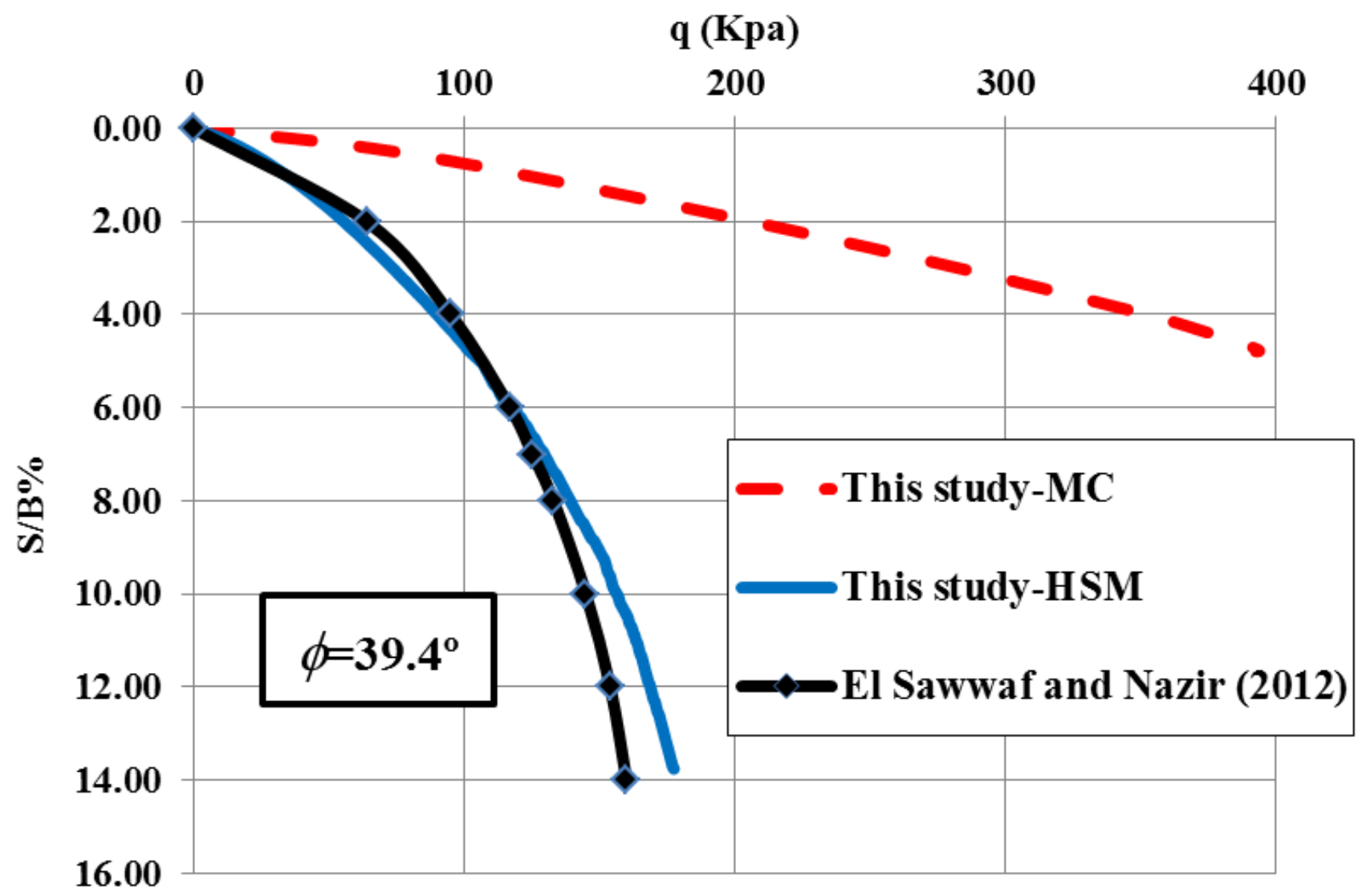

Figure 2

The load-settlement curve of dense sandy soil for various models 


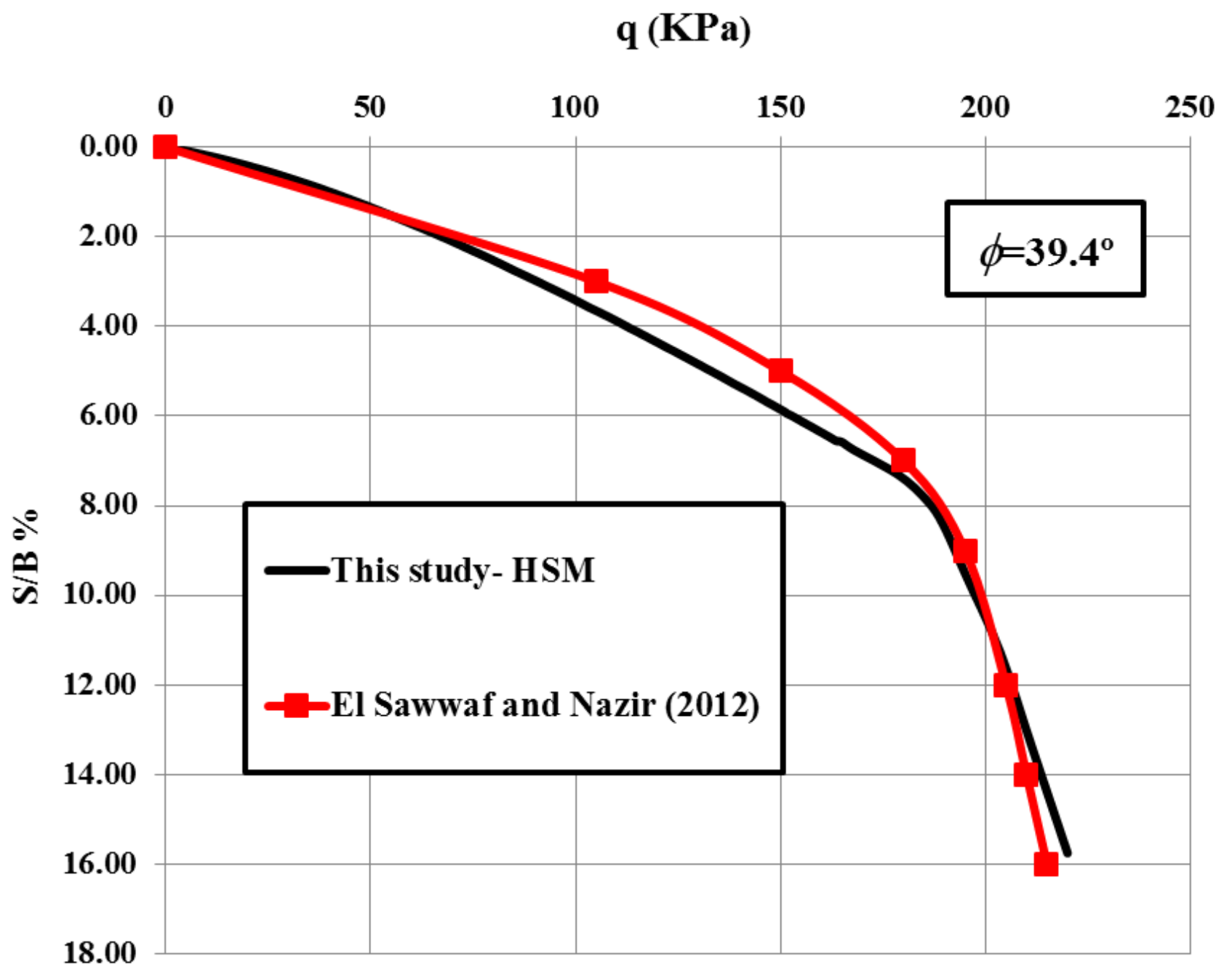

Figure 3

The load-settlement curve of reinforced sand with one geogrid layer 


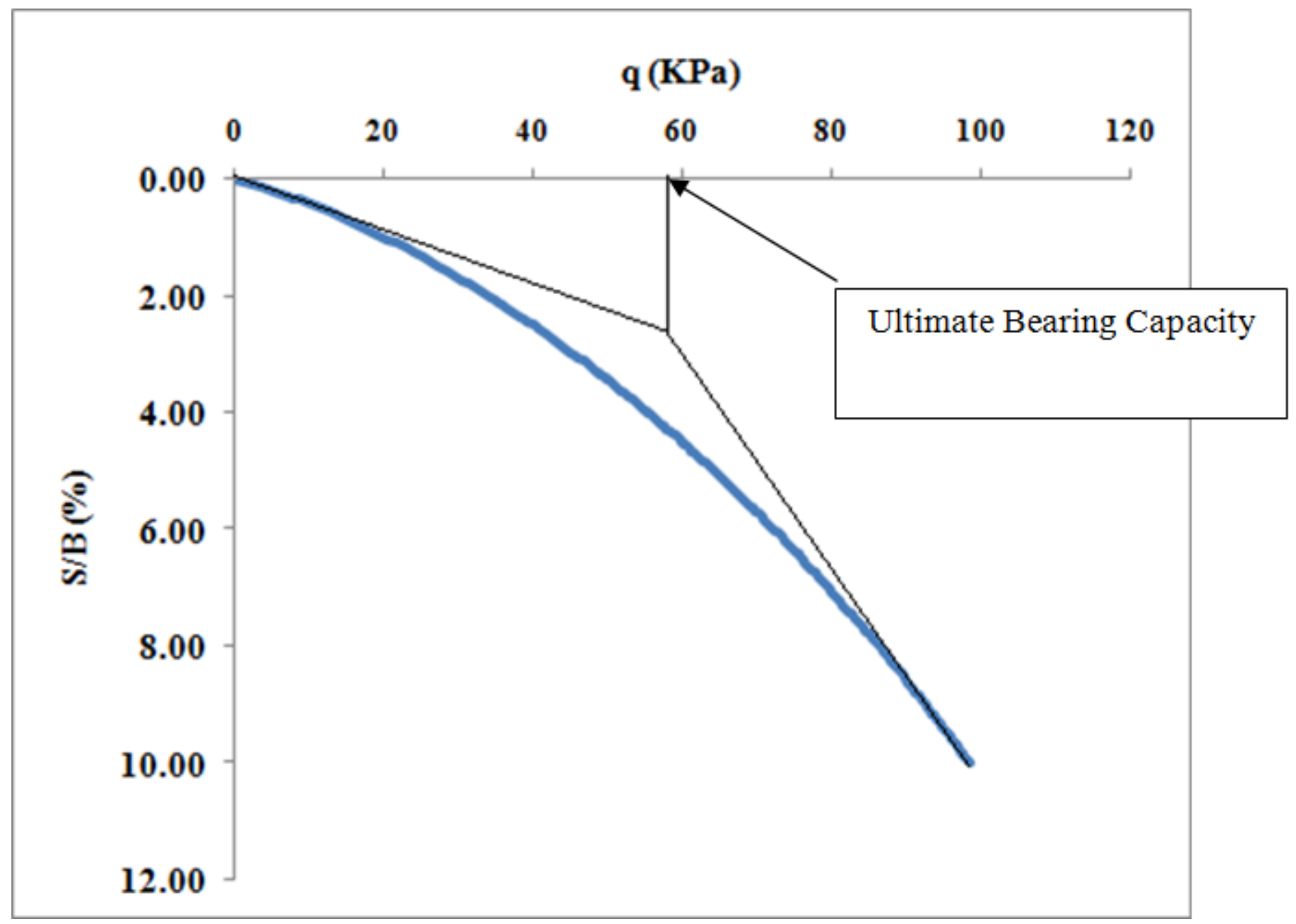

Figure 4

Bearing capacity calculation 


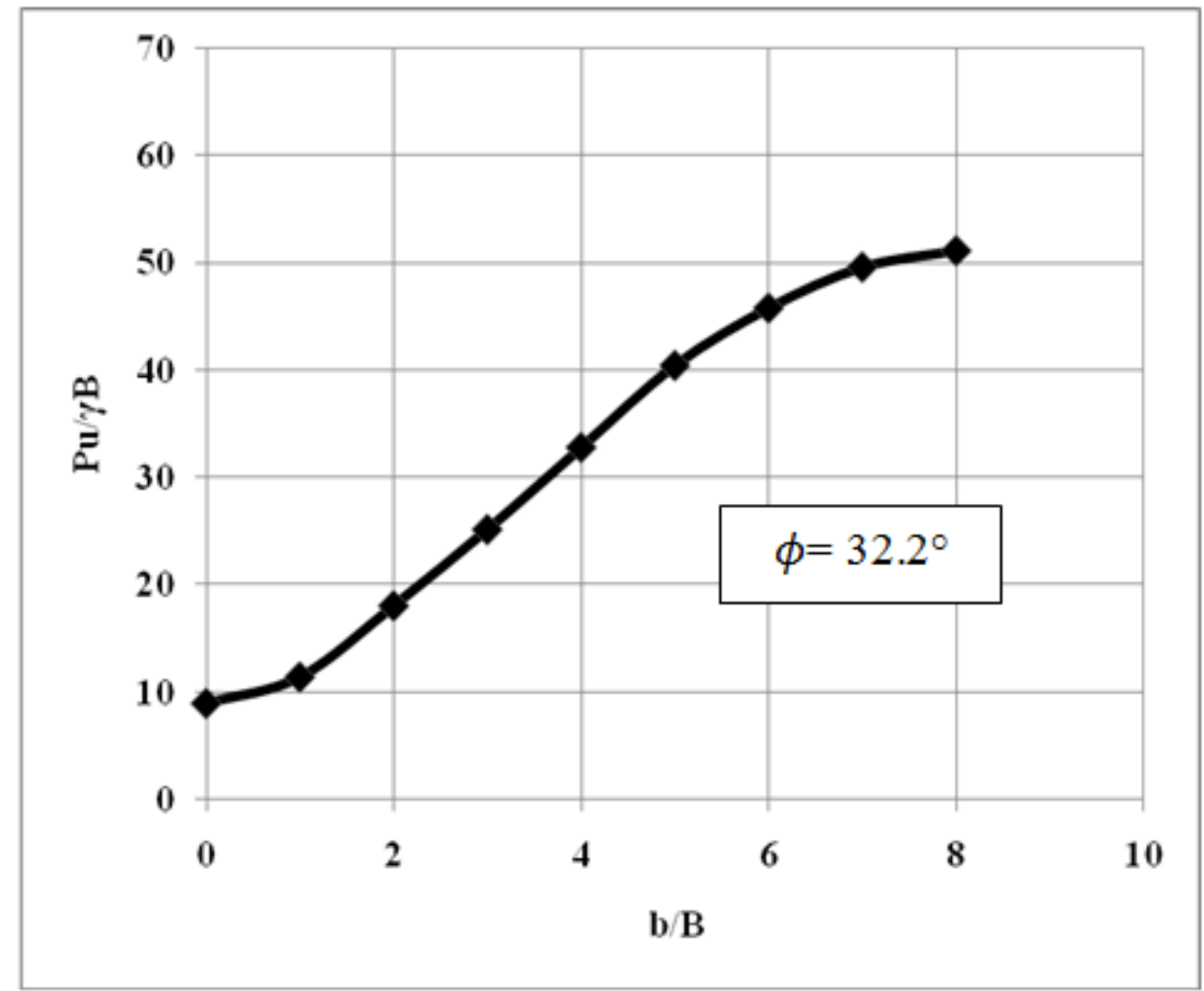

\section{Figure 5}

Variation in $P u / \gamma B$ with edge distance for unreinforced loose sand $(\mathrm{H}=3 \mathrm{~B})$

\section{Figure 6}

Effect of distance from the pit on the expansion of deformation and displacement under the strip foundation in the case of unreinforced granular soil

\section{Figure 7}

Effect of distance from the pit on the expansion of the plastic points of the hardening model (HSM)

\section{Figure 8}

Variation in $P u / \gamma B$ with edge distance for adjacent loose sand excavation 


\section{Figure 9}

Variation in $P u / y B$ with edge distance for loose sand and the impact of multilayer reinforcement

\section{Figure 10}

The change in bearing capacity ratio with the multilayer reinforcements

\section{Figure 11}

Expanding hardening plastic points

\section{Figure 12}

The changes in final loading capacity with a setback for unreinforced sandy soil

\section{Figure 13}

Variation in $P u / \gamma B$ with a setback for dense sand and the effect of multilayered reinforcement

\section{Figure 14}

Bearing capacity ratio with the number of geosynthetics for dense sand

\section{Figure 15}

The changes in (S/B) with b/B for dense and loose sands.

Figure 16 
Impact of the distance between strip foundations on the coefficient of interference of adjacent foundations on reinforced granular soil with a depth ratio of $H / B=3$

\section{Figure 17}

Effect of the length of reinforcing layers on the coefficient of interference of adjacent strip foundations in granular soil with a friction angle of $32.2^{\circ}$ at $\mathrm{H}=3 \mathrm{~B}$

\section{Figure 18}

Expanding plastic dots in the area between adjacent strip foundations

\section{Figure 19}

Expanding total strains in the area between adjacent strip foundations 